\title{
Approaches for Stimulating Proliferation of Stem Cells in Vitro
}

\author{
Weilong Liu, Hui Li, Cai Li* \\ State Key Laboratory of Oral Diseases, West China Hospital of Stomatology, Sichuan University, Chengdu 610041, \\ China \\ Email: drliulei@163.com \\ Conflict-of-interest statement: All authors declare no conflict of interest related to this publication.
}

\begin{abstract}
With the increasing incidence rates in the complex human diseases, e.g., Alzheimer's disease, spinal cord injury, and diabetes, there exists an urgent need to search for more effective and efficient therapies. Cell-based therapy has been considered to be a novel and effective therapeutic approach for the great potential of stem cells in their self-renewal and multipotential differentiational capacity. However, a major difficulty with the success of stem cell therapy is the availability of stem cells. The most serious issue is that only a limited number of stem cells can be extracted from adult tissue due to the decreasing frequency and differentiation potential with age. In order to achieve successful cell-based therapy, extensive ex vivo proliferation of stem cells is urgently required. Therefore, approaches to stimulate proliferation of stem cells are discussed in this article.
\end{abstract}

Key words: Stem cells; stimulate; proliferation; cytokines; growth factors; genes

\section{Introduction}

Recent advances in stem cell research have attracted great attention. Stem cells can be introduced into tissues or organs to replace diseased or damaged cells with minimal risk of rejection and side effects, and can therefore be applied for disorders of the bone/cartilage, lung, liver and diabetic diseases [1-3]. A large number of stem cells should be prepared to achieve satisfactory therapy. A recent consensus indicates that $10^{8}$ cells total or $1 \times 10^{6}$ cells per $\mathrm{kg}$ recipient weight must be administered in mesenchymal stem cells (MSC) therapies [4]. However, stem cells extracted from tissues or organs are scarce. Furthermore, the proliferation of stem cells is limited. A number of disorders of stem cells have been observed during long-term in vitro culture [5,6]. And stem cells tend to loss properties of stemness after serial passaging. Wagner et al. [7] found that long-term cultured MSCs exhibit anomalous morphology and decreased expression of MSCs-specific surface antigens, and the self-renewal potency of MSCs declines. As cells approach senescence, their proliferation slows down and differentiation potential decreases. Therefore, approaches for promoting their proliferation in vitro are urgently needed. Here we summarize the common and effective approaches in stimulating the proliferation of stem cells.

\section{Stem Cell Proliferation in Vitro}

Stem cells are rare cells that are capable of reproducing themselves and differentiating into a variety of cells, which reside in a defined anatomical compartment that includes cellular and extracellular components [8-11]. Cells, blood vessels, matrix proteins, and the three-dimensional space that are formed from this architecture provide a highly specialized microenvironment for stem cells [10]. Contact and communication between these elements are critical for stem cell self-renewal and multipotency. Nevertheless, stem cells culture in vitro is an extremely complex process, in which cells are grown under specific conditions. The growth of these cells is a highly unnatural process in vitro condition. Cells are removed from tissues and artificially cultured in various culture vessels. Vitamins, minerals, and growth factors are added to maintain cell viability. The structure and function between in vitro and in vivo are different. Firstly, living tissues have highly complex architecture and are three-dimensional (3D) in structure. The interaction between adjacent cell types is quite distinct from that in vitro cell culture. Furthermore, adipose tissue-derived stem cells (ASCs) naturally reside in a specific niche with low oxygen tension, where the $\mathrm{O}_{2}$ tension is less than $4 \%[12,13]$. However, ASCs are normally cultured at normal atmospheric oxygen 
tension (20-21\%), which does not represent their normal physiological condition [14]. It has been demonstrated that hMSC at $20 \% \mathrm{O}_{2}$ exhibited significantly increased oxidative stress, DNA damage markers, and telomere shortening rates, compared with cells grown at $3 \% \mathrm{O}_{2}$ [15]. Conversely, numerous studies have demonstrated that ASCs under hypoxia showed the greater number of cells and shorter population doubling time, and oxygen tension as low as $2 \%$ had the greatest impact on cell growth [16-18].

For clinical applications, stem cells must be sufficiently expanded. Therefore, external stimulation applied to improve proliferation of stem cells is essential. Moreover, it has been demonstrated that certain culture conditions, including the use of specific atmospheric conditions and culture substrates, exert positive effects on not only the proliferation rate, but also the extent of proliferation. For instance, low oxygen condition, suitable extracellular matrix (ECM), small molecules compounds have been applied to stimulate the proliferation of stem cells in vitro [19-21]. Low oxygen condition largely mimics normal physiological condition of tissues. Small molecules are active compounds reversibly and specifically modulating signaling pathways. A mass of small molecules have been found to play profound effect on the maintenance and fate-determination of stem cells [22-24]. Because of the advantages such as target-specificity, convenience of application, and low cost, they emerge as promising approaches to improve stem cells therapy [25]. Specific bioactive ECM components determine stem cell fate through the interactions of ECM with stem cells. However, some disadvantages of these strategies limit the application. Low oxygen condition was reported to lack standard protocol. It is difficult to ensure the source and quality of ECM in large-scale cell culture. It remains challenging to preserve the function of stem cells during long-term passaging by specific small-molecule.

\section{Approaches to Stimulate Proliferation of Stem Cells in Vitro}

\subsection{Growth Factors or Cytokines}

Most growth factors are pleiotropic, causing multiple biological effects. They bring about changes in motility, proliferation, morphogenesis and survival. Various growth factors or cytokines, when added to culture medium, accelerate stem cells proliferation, including basic fibroblast growth factor (b-FGF), Platelet-derived growth factor (PDGF), and vascular endothelial growth factor (VEGF) [26-30]. For example, PDGF could stimulate the MSCs proliferation rapidly and promote their secretion to form the extracellular matrix. Qiu et al. [28] found the proliferative capacity of umbilical cord mesenchymal stem cells (UCMSCs) has been markedly improved in the presence of PDGF in a dose-dependent manner, and $50 \mathrm{ng} / \mathrm{ml}$ PDGF exerted the most profound effects on MSC proliferation. Platelets contain lots of cytokines, including PDGF, transforming growth factor beta (TGF- $\beta$ ), insulin-like growth factor-1 (IGF-1), and VEGF in their $\alpha$-granules. As the concentration of platelets rises in human platelet-rich plasma (hPRP), the amount of cytokine increases accordingly [29]. Numerous researches had been performed to assess the effect of hPRP on the viability and proliferation of cells and their results demonstrated that hPRP can stimulation cell proliferation [31-35]. Tavakolinejad et al. [36] have also found that treatment with hPRP resulted in a statistically significant increase in cell proliferation of human adipose-derived stem cells. In addition to human adipose-derived stem cells, increased proliferation rate for other types of stem cells with hPRP as the cell culture supplement was confirmed [37-40]. And the fastest proliferation was observed when hPRP was supplemented in a $10 \%$ concentration. Furthermore, the use of hPRP avoids both safety and ethical concerns associated with the use of FBS [41]. However, there are several issues to be defined for the application of hPRP. First, different hPRP preparations methods are used, eliciting different responses that cannot be compared, standardization of hPRP preparations is thus urgently needed. Furthermore, although hPRP increased cell proliferation, divergences were found regarding the stem cell differentiation capacity $[31,42,43]$. There is no exclusive molecule responsible for the effective proliferation of stem cells in hPRP-supplemented cultures, but is the combination of several molecules. The concrete mechanism is still under exploration. In general, growth factor is secreted by normal cells without drug toxicity and immune rejection. In addition, the application of growth factors is universal to promote stem cell proliferation, which can be used for various stem cell types [28, 44-46]. While individual growth factors have advantages, combination treatments of growth factors seem to be more beneficial due to their synergistic effect on stem cells. Composite treatment with PDGF, b-FGF and TGF $\beta 1$ appears to be a good alternative for MSCs proliferation in vitro to replace serum [44]. And Salehinejad et al. [46] found combination EGF and FGF 
amplified the proliferation of human umbilical cord mesenchymal stem cells. Therefore, combination treatments of growth factors may be a good choice for proliferation of stem cells in vitro.

\subsection{Co-Culture System}

Co-cultures denote the growth of different cell types in a shared medium, where the physical contact between cell types might have influence on the cellular function, which may be related with cell contact, paracrine signaling, soluble factors and inherent feedback. Sertoli cells are well known as the "nurse cells," which can secrete many kinds of cytokines, including epithelial growth factor (EGF), interleukin-6 (IL-6), stem cell factor (SCF), glial cell line-derived neurotrophic factor (GDNF), TGF, IGF-1, and so on [47]. Recent investigations have shown that using sertoli cells in co-culture can improve cell growth rates. Co-culture with Sertoli cells was reported to enhance the proliferation of neural stem cells, bone marrow mesenchymal stem cells (BMMSCs) and UCMSCs [48-50]. Sertoli cells in co-culture positively affected the amount of stem cells via upregulation of genes involved in the regulation of cell cycle progression. Tian et al. [49] found that Sertoli cells stimulated proliferation of BMMSCs in vitro via the PI3K/AKT pathway, and co-cultured BMMSCs showed a higher proportion of cells in the S phase and a lower proportion of cells in G0/G1-phase without impacting the apoptosis of BMMSCs. Previous researches have reported that the $\mathrm{PI} 3 \mathrm{~K} /$ Akt pathway is a survival pathway that regulates cell proliferation, apoptosis, differentiation, and migration [51]. The upstream stimulators of the pathway include various growth factors, cytokines, and foreign molecules. The activation of Akt mediates a cascade of responses of downstream targets that regulate cellular functions [52-55]. For example, activated Akt increases cell survival via bcl-2, and promotes cell proliferation via the activation of mammalian target of rapamycin (mTOR) [51, 56]. The proliferation efficacy of the PI3K/Akt pathway involved in many types of stem cells, including mesenchymal stem cells, embryonic stem cell, and endothelial progenitor cells [57-59]. In short, the interaction between adjacent cell types is quite distinct from that in vitro cell culture. Co-culture systems are effective in promoting the proliferation of stem cells by means of the interactions of two different cell types. Although co-culture systems have certain limitations, such as low proliferation efficacy, they provide a more realistic microenvironment and information than the individual cell culture system.

\subsection{Interactions with the Extracellular Matrix (ECM)}

Certain cellular interactions with the extracellular matrix (ECM) significantly influence stem cell behavior. Fascinating data continues to mount on the important influence of ECM has on stem cell fate, with particular emphasis on the interactions of ECM ligands with cell surface receptors [60]. In addition, it has been shown that ECM-based control of the cell may occur through multiple physical mechanisms, such as ECM geometry at the micro- and nanoscale, ECM elasticity, or mechanical signals transmitted from the ECM to the cells. Li et al. [61] reported that proliferation of synovium-derived stem cells (SDSCs) on the ECM of fetal SDSCs was superior to proliferation on the ECM of adult SDSCs in promoting cell proliferation. Meanwhile, the ECM produced by MSCs from 3-month-old mice (young ECM), unlike the one by MSCs of 18-month-old mice, better-supported self-renewal and bone formation of MSCs isolated from old mice [62]. In fact, the ECM of young mouse MSCs contains higher amounts of collagen and lower amounts of phosphate, and the ratio or the amount of calcium phosphate was proposed to affect proliferation and viability [63]. Furthermore, the proliferative capacity of human MSCs reportedly increased by eight doublings when cultivated on a plate coated with $\mathrm{ECM}-\mathrm{gel}^{\mathrm{R}}$, a commercially available mixture of basement membrane proteins that includes fibronectin, laminin-1, laminin-5, and collagen IV [64]. In principle, the ECM largely represents the native cellular and tissue microenvironment [65]. And there is increasing data showing great interest of capitalizing on the innate ability of the ECM to modulate stem cell fate $[66,67]$. However, the composition and activity of the ECM are affected by the culture conditions of the stem cells [68]. And different combinations of ECM proteins have been shown to result in variable consequences $[69,70]$, more ECM proteins or combinations should be explored to fully understand their roles on stem cells behavior. Above all, it is difficult to ensure the source and quality of ECM in large-scale cell culture. Future work should focus on identifying and characterizing the chemical and physical mechanism of action of specific bioactive ECM components on stem cells. 


\subsection{Physical Factors}

Cooper et al. discovered that animal cells proliferate more rapidly in oxygen concentrations lower than $20 \%$ $\mathrm{O}_{2}$ (hypoxia) in 1958 [71]. Since then, the role of hypoxic culture in enhanced proliferation has been observed in a diversity of stem cell types [72-76]. Yamamoto et al. [76] reported that ASCs cultured in $2 \%$ $\mathrm{O}_{2}$ show a 1.5-fold increase in proliferation over 6 weeks of culture. Low oxygen culture conditions have shown to trigger activation of HIF- $1 \alpha$ known to regulate cell proliferation [77]. The ERK1/2 and Akt pathway were also involved. Akt was phosphorylated in the hypoxic culture of ASCs. Activated Akt may stabilize HIF-1 $\alpha$ as a survival response in ASCs. And the levels of VEGF and FGF-2 mRNA and protein in the ASCs were significantly enhanced under hypoxia. Furthermore, hypoxic treatment shows an enhanced expression of the stemness markers OCT4, NANOG, REX1 and SOX2, supporting cells to maintain their stemness properties. Collectively, hypoxic culture conditions are favorable for ex vivo stem cell proliferation, which allows the production of many stem cells from a few donor cells. And it provides a useful culture method for the large-scale production of stem cells that will be required in regenerative medicine. However, there are controversies related to proliferation of stem cells under hypoxia $[78,79]$, and the effect of hypoxia on the proliferation capacity of dental-derived stem cells is limited [79]. Further studies are required due to the lack of standardization in cell culture techniques.

Low-level laser irradiation also emerges as an attractive approach to stimulate cell proliferation. Previous studies have shown that low-level laser irradiation therapy can increase cell proliferation [80, 81]. Wavelengths of 600 to $700 \mathrm{~nm}$ were commonly used to stimulate cell proliferation. Mvula et al. [82] demonstrated that irradiation of human ADSCs using a laser at a wavelength of $635 \mathrm{~nm}$ and dose of 5.0 $\mathrm{J} / \mathrm{cm}_{2}$ positively influenced cell proliferation and viability, as well as the expression of proteins, such as EGF. The proliferative efficacy of laser irradiation on BMSCs and ASCs has also been verified [83]. However, the parameters used for the laser therapy are limited and sometimes conflicting due to lack of standardization, as the wavelength, power density, the radiation time can influence in the achievement of the desired biological properties [84]. And the exact molecular mechanism by which LLLT exerts its effects on cell proliferation is not completely understood. Further studies are needed to standardize the laser parameters to improve the yield of stem cells in culture.

\subsection{Three-Dimensional (3D) System}

Recently, various attempts have been reported to expand MSC in three-dimensional (3D) environments, based on suspension culture in the presence of dynamic flow [85, 86], on microcarrier beads [87-89] or on a rotating bed bioreactor system [90, 91]. Papadimitropoulos et al. [94] developed a system for the proliferation of MSC which entirely bypasses the use of $2 \mathrm{D}$ surfaces by seeding and expanding fresh bone marrow preparations directly within the pores of 3D scaffolds under perfusion flow. The 3D-perfusion system generated a stromal tissue that could be enzymatically treated to yield CD45-MSC. As compared to 2D-expanded MSC, those derived from 3D-perfusion culture after the same time (3 weeks) or a similar extent of proliferation (7-8 doublings) better maintained their progenitor properties, as assessed by a 4.3-fold higher clonogenicity. Different from the conventional 2D culture system, 3D system largely mimicked tissue-specific microenvironment or niche, preserved better their early progenitor properties, and maintained a higher clonogenicity and a superior multilineage differentiation capacity. Above all, 3D proliferation streamlined conventional labor-intensive processes, was prone to automation and scalability within closed bioreactor systems [92]. However, it is challenging to obtain a range of materials with identical geometries. Many parameters are pertinent to the experimental outcome including scaffold composition, pore size, porosity, and pore interconnectivity [93], which are time-consuming and troublesome. And 3D culture showed unclear potential for long-term serial culture. Overall, 3D culture system provides a significantly expanded space for cell growth, which results in effective proliferation and high yields of cells. As a promising strategy for stem cells proliferation, 3D culture shows unique advantages and has great potential to achieve large-scale production for cell therapy.

\subsection{Genetic Modification}

Stem cells are excellent carriers of genes and can be genetically manipulated for gene overexpression. Genetic modification of stem cells with genes encoding for tissue-specific cytokines can promote 
application of stem cells. Nanog and Oct4 are transcription factors required to maintain the undifferentiated state and self-renewal of stem cells [94, 95]. In embryonic stem cells, knockout or knockdown of Nanog abolishes both self-renewal and pluripotency whereas Nanog overexpression enables their propagation for multiple passages during which the cells remain pluripotent [96]. The effects of Nanog and Oct4 overexpression on MSCs were also examined. It was shown that Oct4-expressing MSCs displayed high proliferative capacity [97], and ectopic expression of Nanog increased growth rate of MSCs [98]. It was expected that Nanog and Oct4 promoted cell proliferation of MSCs by acting as a transcriptional regulator. Compared with control MSCs, overexpression of Nanog enhanced the proliferation rate of MSCs by average 1.67-fold, and Oct4 overexpression increased proliferation rate of MSCs by average 1.51-fold. During passage, control MSCs became flat at passage 10 and began to lose MSC morphology, while Nanog or Oct4 overexpressing MSCs still retained the morphology of MSCs, showing Nanog or Oct4 overexpression not only promoted proliferation rate of MSCs, but also maintained the morphology of MSCs. Overall, transgene expression to effectively genetically modify stem cells provided an efficient tool for ex vivo proliferation of stem cells. However, genetic-modulated stem cells possess potential risk of mutation or malformation [27]. The proliferation efficacy of genetic modification is low, requiring professional skills. And it is difficult to achieve large-scale production. As the development of molecular biology and cell biology, it might be a promising strategy for clinical application in the future.

\section{Conclusion}

In recent years, great leaps have been made in the field of stem cell proliferation. Various microenvironment factors, 3D culture system, physical factors, genetic modification exert enormous influence on stem cell proliferation, which lead to changes in proliferation, morphogenesis and survival of stem cells. Relevant research progress has provided significant criteria in establishing ideal approaches for proliferation of stem cells in vitro. However, some obvious disadvantages of these approaches can be observed, including low efficacy of proliferation, complicated procedures involved, and lack of standardization in cell culture techniques. Hence, the improvement of these approaches remains a haunting issue in the field of cell biology. From our studies and previous literature, the full realization of obtaining sufficient stem cells in vitro requires further explorations in these promising research directions: 3D culture system, optimal combinations and concentrations of various factors, appropriate physical factors.

Acknowledgment. This study was supported by National Natural Foundation of China [81271096, 81670951] and Fundamental Research Funds for the Central Universities of China [2011SCUD4B14].

\section{References}

1. K. Sadat, S. Ather, W. Aljaroudi, J. Heo, A. E. Iskandrian and F. G. Hage, "The effect of bone marrow mononuclear stem cell therapy on left ventricular function and myocardial perfusion," Journal of Nuclear Cardiology Official Publication of the American Society of Nuclear Cardiology, vol. 21, no. 2, pp. 1-17, 2014.

2. P. Rimmelé, S. Lofek-Czubek and S. Ghaffari, "Resveratrol increases the bone marrow hematopoietic stem and progenitor cell capacity," American Journal of Hematology, vol. 89, no. 12, pp. 235-238, 2014.

3. B. Larijani, B. Arjmand, N. Ahmadbeigi, K. Falahzadeh, M. Soleimani, F. A. Sayahpour and H. R. Aghayan, "A simple and cost-effective method for isolation and expansion of human fetal pancreas derived mesenchymal stem cells, " Archives of Iranian Medicine, vol. 18, no. 11, pp. 770-775, 2015.

4. Y. Miura, "Human bone marrow mesenchymal stromal/stem cells: current clinical applications and potential for hematology," International Journal of Hematology, vol. 103, no. 2, pp. 122-128, 2016.

5. N. Baker, L. B. Boyette and R. S. Tuan, "Characterization of bone marrow-derived mesenchymal stem cells in aging," Bone, vol. 70, pp. 37-47, 2015.

6. J. Kim, J. W. Kang, J. H. Park, Y. Choi, K. S. Choi, K. D. Park, D. H. Baek, S. K. Seong, H. K. Min and H. S. Kim, "Biological characterization of long-term cultured human mesenchymal stem cells," Archives of Pharmacal Research, vol. 32, no. 1, pp. 117-126, 2009. 
7. W. Wagner, S. Bork, G. Lepperdinger, S. Joussen, N. Ma, D. Strunk and C. Koch, "How to track cellular aging of mesenchymal stromal cells?," Aging (Albany NY), vol. 2, no. 4, pp. 224-230, 2010.

8. D. L. Jones and A. J. Wagers, "No place like home: anatomy and function of the stem cell niche," Nature reviews Molecular cell biology, vol. 9, no. 1, pp. 11-21, 2008.

9. L. Li, and T. Xie, "Stem cell niche: structure and function," Annual Review of Cell and Developmental Biology, vol. 21, pp. 605-631, 2005.

10.D.T. Scadden, "The stem-cell niche as an entity of action," Nature, vol. 441, no. 7097, pp. 1075-1079, 2006.

11.T. Yin and L. Li, "The stem cell niches in bone," The Journal of clinical investigation. vol. 116, no. 5, pp. 1195-1201, 2006.

12.M. Pasarica, O. R. Sereda, L. M. Redman, D. C. Albarado, D. T. Hymel, L. E. Roan, J. C. Rood, D. H. Burk and S. R. Smith, "Reduced adipose tissue oxygenation in human obesity: evidence for rarefaction macrophage chemotaxis, and inflammation without an angiogenic response," Diabetes, vol. 58, no. 3, pp. 718-725, 2009.

13.H. M. Chung, C. H. Won and J. H. Sung, "Responses of adipose-derived stem cells during hypoxia-enhanced skin-regenerative potential," Expert opinion on biological therapy, vol. 9, no. 12, pp. 1499-1508, 2009.

14.Z. Ivanovic, "Hypoxia or in situ normoxia: the stem cell paradigm," Journal of cellular physiology, vol. 219, no. 2, pp. 271-275, 2009

15.J. C. Estrada, C. Albo, A. Bengurı'a, A. Dopazo, P. Lo’pez-Romero, L. Carrera-Quintanar, E. Roche, E. P. Clemente, J. A. Enrı'quez, A. Bernad and E. Samper, "Culture of human mesenchymal stem cells at low oxygen tension improves growth and genetic stability by activating glycolysis," vol. 19, no. 5, pp. 743-755, 2012.

16.M. G. Valorani, E. Montelatici, A. Germani, A. Biddle, D. D’Alessandro, R. Strollo, M. P. Patrizi, L. Lazzari, E. Nye, W. R. Otto, P. Pozzilli and M. R. Alison, "Pre-culturing human adipose tissue mesenchymal stem cells under hypoxia increases their adipogenic and osteogenic differentiation potentials," Cell Proliferation, vol. 45, no. 3, pp. 225-238, 2012.

17.Y. Xu, P. Malladi, M. Chiou, E. Bekerman, A. J. Giaccia and M. T. Longaker, "In vitro expansion of adipose-derived adult stromal cells in hypoxia enhances early chondrogenesis," Tissue Engineering, vol. 13, no. 12, pp. 2981-2993, 2007.

18.Y. Yang, F. Sun, C. Zhang, H. Wang, G. Wu and Z. Wu, "Hypoxia promotes cell proliferation by modulating E2F1 in chicken pulmonary arterial smooth muscle cells," Journal of Animal Science and Biotechnology, vol. 4, no. 3, pp. 205-210, 2013.

19.E. S. Hwang, J. S. Ok and S. Song, "Chemical and Physical Approaches to Extend the Replicative and Differentiation Potential of Stem Cells," Stem Cell Reviews \& Reports, vol. 12, no. 3, pp. 315-326, 2016.

20.A. I. Hoch and J. K. Leach, "Concise Review: Optimizing Expansion of Bone Marrow Mesenchymal Stem/Stromal Cells for Clinical Applications," Stem Cells Translational Medicine, vol. 3, no. 5, pp. 643-652, 2014.

21.Y. Sun, W. Li, Z. Lu, R. Chen, J. Ling, Q. Ran, R. L. Jilka and X. D. Chen, "Rescuing replication and osteogenesis of aged mesenchymal stem cells by exposure to a young extracellular matrix," The FASEB Journal, vol. 25, no. 5, pp. 1474-1485, 2011.

22.J. Li, S. G. Kim and J. Blenis, "Rapamycin: one drug, many effects," Cell metabolism, vol. 19, no. 3, pp. 373-379, 2014.

23.D. E. Harrison, R. Strong, Z. D. Sharp, J. F. Nelson, C. M. Astle, K. Flurkey, N. L. Nadon, J. E. Wilkinson, K. Frenkel, C. S. Carter, M. Pahor, M. A. Javors, E. Fernandez and R. A. Miller, "Rapamycin fed late in life extends lifespan in genetically heterogeneous mice," Nature, vol. 460, no. 7253, pp. 392-395, 2009.

24.K. J. Pearson, J. A. Baur, K. N. Lewis, L. Peshkin, N. L. Price, N. Labinskyy, W. R. Swindell, D. Kamara, R. K. Minor, E. Perez, H. A. Jamieson, Y. Q. Zhang, S. R. Dunn, K. Sharma, N. Pleshko, L. A. Woollett, A. Csiszar, Y. J. Ikeno, D. L. Couteur, P. J. Elliott, K. G. Becker, P. Navas, D. K. Ingram, N. S. Wolf, Z. Ungvari, D. A. Sinclair and R. D. Cabo, "Resveratrol delays age-related deterioration and mimics transcriptional aspects of dietary restriction without extending life span," Cell metabolism, vol. 8, no. 2, pp. 157-168, 2008.

25.L. L. Lairson, C. A. Lyssiotis, S. Zhu and P. G. Schultz, "Small molecule-based approaches to adult stem cell therapies. Annual review of pharmacology and toxicology," Pharmacology and Toxicology, vol. 53, no. 53, pp. 107-125, 2013.

26.G. Song, Y. Ju and H. Soyama, "Growth and proliferation of bone marrow mesenchymal stem cells affected by type I collagen, fibronectin and bFGF," Materials Science \& Engineering C, vol. 28, no. 8, pp. 1467-1471, 2008. 
27.E. Jeon, Y. R. Yun, W. Kang, S. Lee, Y. H. Koh, H. W. Kim, C. K. Suh and J. H. Jang, "Investigating the Role of FGF18 in the Cultivation and Osteogenic Differentiation of Mesenchymal Stem Cells," Plos One, vol. 7, no. 8, pp. e43982, 2012.

28.P. Qiu, W. Song, Z. Niu, Y. Bai, W. Li, S. H. Pan, S. Sha and J. L. Hua, "Platelet-derived growth factor promotes the proliferation of human umbilical cord-derived mesenchymal stem cells," Cell Biochemistry \& Function, vol. 31, no. 2, pp. 159-165, 2013.

29.J. Shen, Q. Gao, Y. Zhang and Y. He, "Autologous platelet rich plasma promotes proliferation and chondrogenic differentiation of adipose derived stem cells," Molecular Medicine Reports, vol. 12, no. 2, pp. 1298-1303, 2015.

30.J. Pons, Y. Huang, J. Arakawa-Hoyt, D. Washko, J. Takagawa, J. Q. Ye, W. Grossman and H. Su, "VEGF improves survival of mesenchymal stem cells in infarcted hearts," Biochemical \& Biophysical Research Communications, vol. 376, no. 2, pp. 419-422, 2008.

31.A. Mishra, P. Tummala, A. King, B. Lee, M. Kraus, V. Tse and C. R. Jacobs, "Buffered platelet-rich plasma enhances mesenchymal stem cell proliferation and chondrogenic differentiation," Tissue Engineering Part C Methods, vol. 15, no. 3, pp. 431-435, 2009.

32.Y. Feng, Y. Sun, W. Jia and C. Zhang, "Platelet-rich plasma and 1,25(OH)2 vitamin D3 synergistically stimulate osteogenic differentiation of adult human mesenchymal stem cells," Biotechnology Letters, vol. 32, no. 5, pp. 635-642, 2010.

33.N. Kakudo, T. Minakata, T. Mitsui, S. Kushida, F. Z. Notodihardjo and K. Kusumoto, "Proliferation-promoting effect of platelet-rich plasma on human adipose-derived stem cells and human dermal fibroblasts," Plastic \& Reconstructive Surgery, vol. 122, no. 5, pp. 1352-1360, 2008.

34.J. P. Vogel, K. Szalay, F. Geiger, M. Kramer, W. Richter and P. Kasten, " Platelet-rich plasma improves expansion of human mesenchymal stem cells and retains differentiation capacity and in vivo bone formation in calcium phosphate ceramics," Platelets, vol. 17, no. 7, pp. 462-469, 2006.

35.H. M. LI, D. Liu, Y. L. YU and T. Wu, "Experimental research of the promotion effect of autogeneic PRP on osteogenic differentiation of human adipose-derived stem cells in vitro," Chinese Journal of Reparative and Reconstructive Surgery, vol. 23, no. 6, pp. 732-736, 2009.

36.S. Tavakolinejad, M. Khosravi, B. Mashkani, B. A. Ebrahimzadeh, M. N. Sanjar, M. R. Parizadeh and A. D. Hamidi, "The effect of human platelet-rich plasma on adipose-derived stem cell proliferation and osteogenic differentiation," Iranian Biomedical Journal, vol. 18, no. 3, pp. 151-157, 2014.

37.P. R. Amable, M. V. Teixeira, R. B. Carias, J. M. Granjeiro and R. Borojevic, "Mesenchymal Stromal Cell Proliferation, Gene Expression and Protein Production in Human Platelet-Rich Plasma-Supplemented Media," PLoS One, vol. 9, no. 8, pp. e104662, 2014.

38.T. S. Kleplová, T. Soukup, V. Řeháček and J. Suchánek, "Human plasma and human platelet-rich plasma as a substitute for fetal calf serum during long-term cultivation of mesenchymal dental pulp stem cells," vol. 57, no. 3, pp. 119-126, 2014.

39.V. Govindasamy, V. S. Ronald, A. N. B Abdullah, K. R. Ganesan Nathan, Z. A. Aziz, M. Abdullah, R. B. Zain, N. H. Kasim, S. Musa and R. R. Bhonde, "Human platelet lysate permits scale-up of dental pulp stromal cells for clinical applications," Cytotherapy, vol. 13, no. 10, pp. 1221-1233, 2011.

40.B. Chen, H. Sun, H. Wang, H. Kong, F. Chen and Q. Yu, "The effects of human platelet lysate on dental pulp stem cells derived from impacted human third molars," Biomaterials, vol. 33, no. 20, pp. 5023-5035, 2012.

41.C. Rauch, E. Feifel, E. M. Amann, H. P. Spötl, H. Schennach, W. Pfaller and G. Gstraunthaler, "Alternatives to the use of fetal bovine serum: human platelet lysates as a serum substitute in cell culture media," ALTEX, vol. 28, no. 4, pp. 305-316, 2011.

42.D. M. Dohan Ehrenfest, P. Doglioli, G. M. de Peppo, M. Del Corso, J. B. Charrier, "Choukroun's platelet-rich fibrin $(\mathrm{PRF})$ stimulates in vitro proliferation and differentiation of human oral bone mesenchymal stem cell in a dose-dependent way," Archives of oral biology, vol. 55, no. 3, pp. 185-194, 2010.

43.A. Drengk, A. Zapf, E. K. Stürmer, K. M. Stürmer, K. H. Frosch, "Influence of platelet-rich plasma on chondrogenic differentiation and proliferation of chondrocytes," Cells Tissues Organs, vol. 189, no. 5, pp. 317-326, 2008.

44.M. Rodrigues, L. G. Griffith and A. Wells, "Growth factor regulation of proliferation and survival of multipotential stromal cells," Stem Cell Research \& Therapy, vol. 1, no. 4, pp. 32, 2010.

45.J. H. Lee, S. Um, J. H. Jang and B. M. Seo. "Effects of VEGF and FGF-2 on proliferation and differentiation of human periodontal ligament stem cells," cell and tissue research, vol. 348, no. 3, pp. 475-484, 2012. 
46.P. Salehinejad, N. B. Alitheen, A. Mandegary, S. N. Nematollahi-mahani and E. Janzamin, "Effect of EGF and FGF on the expansion properties of human umbilical cord mesenchymal cells," In Vitro Cellular \& Developmental Biology - Animal, vol. 49, no. 7 , pp. 515-526, 2013.

47.M. K. Skinner, "Secretion of growth factors and other regulatory factors," The Sertoli cell, vol. 18, pp. 237-248, 1993.

48.A. I. Othberg, A. E. Willing, D. F. Cameron, A. Anton, S. Saporta, T. B. Freeman and P. R. Sanberg, "Trophic Effect of Porcine Sertoli Cells on Rat and Human Ventral Mesencephalic Cells and hNT Neurons In Vitro," Cell Transplantation, vol. 7, no. 2, pp. 157-164, 1998.

49.H. Tian, M. Guo, Y. Zhuang, J. Chu and S. Zhang, "Enhanced proliferation of bone marrow mesenchymalstem cells by co-culture with TM4 mouse Sertoli cells: involvement of the EGF/PI3K/AKT pathway," Molecular \& Cellular Biochemistry, vol. 393, no. 1-2, pp. 155-164, 2014.

50.F. Zhang, Y. Hong, W. Liang, T. Ren, S. Jing and J. Lin, "Co-culture with Sertoli cells promotes proliferation and migration of umbilical cord mesenchymal stem cells," Biochemical \& Biophysical Research Communications, vol. 427, no. 1, pp. 86-90, 2012.

51.J. Chen, "Multiple signal pathways in obesity-associated cancer," Obesity Reviews, vol. 12, no. 12, pp. 1063-1070, 2011.

52.A. Brunet, A. Bonni, M. J. Zigmond, M. Z. Lin, P. Juo, L. S. Hu, M. J. Anderson, K. C. Arden3, John Blenis and M. E. Greenberg, "Akt Promotes Cell Survival by Phosphorylating and Inhibiting a Forkhead Transcription Factor," Cell, vol. 96, no. 6, pp. 857-868, 1999.

53.V. K. Srivastava, R. K. Gara, M. L. B. Bhatt, D.P. Sahu and D. P. Mishra, "Centchroman inhibits proliferation of head and neck cancer cells through the modulation of PI3K/mTOR Pathway," Biochemical \& Biophysical Research Communications, vol. 401, no. 4, pp. 40-45, 2011.

54.N. Li, X. Bu, X. Tian, P. Wu and L. Y. P. Huang, "Fatty acid synthase regulates proliferation and migration of colorectal cancer cells via HER2-PI3K/Akt signaling pathway," Nutrition \& Cancer, vol. 64, no. 6, pp. 864-870, 2011.

55.J. Kizhakkayil, F. Thayyullathil, S. Chathoth, A. Hago, M. Patel and S. Galadari, "Modulation of curcumin-induced Akt phosphorylation and apoptosis by PI3K inhibitor in MCF-7 cells," Biochemical \& Biophysical Research Communications, vol. 394, no. 3, pp. 476-481, 2010.

56.P. Liu, H. Cheng, T.M. Roberts and J. J. Zhao, "Targeting the phosphoinositide 3-kinase pathway in cancer," Nature reviews Drug discovery, vol. 8, no. 8, pp. 627-644, 2009.

57.M. Marędziak, K. Tomaszewski, P. Polinceusz, D. Lewandowski and K. Marycz, "Static magnetic field enhances the viability and proliferation rate of adipose tissue-derived mesenchymalstem cells potentially through activation of the phosphoinositide 3-kinase/Akt (PI3K/Akt) pathway," Electromagnetic Biology and Medicine, pp. 1-10, 2009.

58.Y. Zhang, J. Lv, H. Guo, X. Wei, W. Li and Z. Xu, "Hypoxia-induced proliferation in mesenchymal stem cells and angiotensin II-mediated PI3K/AKT pathway," Cell biochemistry and function, vol.33, no. 2, pp. 51-58, 2015.

59.W. Li, D. Du, H. Wang, Y. Liu, X. Lai, F. Jiang, D. Chen, Y. Zhang, J. Zong and Y. Li, "Silent information regulator 1 (SIRT1) promotes the migration and proliferation of endothelial progenitor cells through the PI3K/Akt/eNOS signaling pathway," International journal of clinical and experimental pathology, vol. 8, no. 3, pp. 2274-2287, 2015.

60.W. P. Daley, S. B. Peters and M. Larsen, "Extracellular matrix dynamics in development and regenerative medicine," Journal of Cell Science, vol. 121, no. 3, pp. 255-264, 2008.

61.J. Li, K. C. Hansen, Y. Zhang, C. Dong, C. Z. Dinu, M. Dzieciatkowska and M. Peia, "Rejuvenation of chondrogenic potential in a young stem cell microenvironment," Biomaterials, vol. 35, no. 2, pp. 642-653, 2013.

62.C. H. Sun, X. Liu, L. Qi, J. P. Xu, J. Zhao, Y. Zhang, S. L. Zhang and J. Y. Miao, "Modulation of vascular endothelial cell senescence by integrin $\beta 4$," Journal of Cellular Physiology, vol. 225, no. 3, pp. 673-681, 2010.

63.D. P. Pioletti, H. Takei, T. Lin, P. V. Landuyt, Q. J. Ma, S. Y. Kwonb and K.-L P. Sunga, "The effects of calcium phosphate cement particles on osteoblast functions," Biomaterials, vol. 21, no. 11, pp. 1103-1114, 2000.

64.U. Lindner, J. Kramer, J. Behrends, B. Driller, N. O. Wendler, F. Boehrnsen, J. Rohwedel and P. Schlenke. "Improved proliferation and differentiation capacity of human mesenchymal stromal cells cultured withbasement-membrane extracellular matrix proteins," Cytotherapy, vol. 12, no. 8, pp. 992-1005, 2010.

65.D. E. Discher, D. J. Mooney and P. W. Zandstra, "Growth factors, matrices, and forces combine and control stem cells," Science, vol. 324, no. 5935, pp. 1673-1677, 2009. 
66.F. Guilak, D. M. Cohen, B. T. Estes, J. M. Gimble, W. Liedtke and C. S. Chen, "Control of stem cell fate by physical interactions with the extracellular matrix," Cell Stem Cell, vol. 5, no. 1, pp. 17-26, 2009.

67.A. J. Engler, S. Sen, H. L. Sweeney and D. E. Discher, "Matrix elasticity directs stem cell lineage specification," Cell, vol. 126 , no. 4, pp. 677-689, 2006.

68.M. L. Decaris, J. K. Leach, "Design of experiments approach to Engineer cellsecreted matrices for directing osteogenic differentiation," Annals of biomedical engineering, vol. 39, no. 4, pp. 1174-1185, 2011.

69.A. K. Kundu, C. B. Khatiwala and A. J, "Putnam. Extracellular matrix remodeling, integrin expression, and downstream signaling pathways influence the osteogenic differentiation of mesenchymal stem cells on poly(lactide-co-glycolide) substrates," Tissue Engineering Part A, vol. 15, no. 2, pp. 273-283, 2008.

70.J. A. Santiago, R. Pogemiller and B. M. Ogle, "Heterogeneous differentiation of human mesenchymal stem cells in response to extended culture in extracellular matrices," Tissue Engineering Part A, vol. 15, no. 12, pp. 3911-3922, 2009.

71.P. D. Cooper, A. M. Burt and JN Wilson, "Critical Effect of Oxygen Tension on Rate of Growth of Animal Cells in Continuous Suspended Culture," Nature, vol. 182, no. 4648, pp. 1508-1509, 1958.

72.I. Berniakovich and M. Giorgio, "Low oxygen tension maintains multipotency, whereas normoxia increases differentiation of mouse bone marrow stromal cells," International Journal of Molecular Sciences, vol. 14, no. 1, pp. 2119-2134, 2013.

73.S. V. Boregowda, V. Krishnappa, J. W. Chambers, P. V. Lograsso, W. T. Lai, L. A. Ortiz and D. G. Phinney, "Atmospheric Oxygen Inhibits Growth and Differentiation of Marrow-Derived Mouse Mesenchymal Stem Cells via a p53-Dependent Mechanism: Implications for Long-Term Culture Expansion," Stem Cells, vol. 30, no. 5, pp. 975-987, 2012.

74.S. P. Hung, J. H. Ho, Y. R. V. Shih, T. Lo and O. K. Lee, "Hypoxia promotes proliferation and osteogenic differentiation potentials of human mesenchymal stem cells," Journal of Orthopaedic Research, vol. 30, no. 2, pp. 260-266, 2012.

75.W. L. Grayson, F. Zhao, B. Bunnell and T. Ma, "Hypoxia enhances proliferation and tissue formation of human mesenchymal stem cells," Biochemical \& Biophysical Research Communications, vol. 358, no. 3, pp. 948-953, 2007.

76.Y. Yamamoto, M. Fujita, Y. Tanaka, I. Kojima, Y. Kanatani, M. Ishihara and S.Tachibana, "Low Oxygen Tension Enhances Proliferation and Maintains Stemness of Adipose Tissue-Derived Stromal Cells," Bioresearch Open Access, vol. 2, no. 3, pp. 199-205, 2013.

77.P. R. Crisostomo, Y. Wang, T. A. Markel, M. Wang, T. Lahm and D. R. Meldrum. "Human mesenchymal stem cells stimulated by TNF- $\alpha$, LPS, or hypoxia produce growth factors by an NFkB- but not JNK-dependent mechanism," American Journal of Physiology-Cell Physiology, vol. 294, no. 3, pp. c675-682, 2008.

78.J. R. Choia, B. Pingguan-Murphya, W. A. B. W. Abasa, M. A. N. Azmib, S. Z. Omarb, K. H. Chuac and W. K. Z. W. Safwania, "Impact of low oxygen tension on stemness, proliferation and differentiation potential of human adipose-derived stem cells," Biochemical and biophysical research communications, vol. 448, no. 2, pp. 218-224, 2014.

79.S. B. Werlea, P. Chagastelles, P. Pranke and L. Casagrande, "The effects of hypoxia on in vitro culture of dental-derived stem cells," Archives of oral biology, vol. 68, no. 2, pp. 13-20, 2016.

80.A. Stein, D. Benayahu, L. Maltz and U. Oron, "Low-level laser irradiation promotes proliferation and differentiation of human osteoblasts in vitro," Photomedicine \& Laser Surgery, vol. 23, no. 2, pp. 161-166, 2005.

81.H. Tuby, L. Maltz and U. Oron, "Low-level laser irradiation (LLLI) promotes proliferation of mesenchymal and cardiac stem cells in culture," Lasers in Surgery \& Medicine, vol. 39, no. 4, pp. 373-378, 2007.

82.B. Mvula, T. J. Moore and H. Abrahamse, "Effect of low-level laser irradiation and epidermal growth factor on adult human adipose-derived stem cells," Lasers in Medical Science, vol. 24, no. 1, pp. 33-39, 2010.

83.J. A. D. Villiers, N. N. Houreld and H. Abrahamse, "Influence of Low Intensity Laser Irradiation on Isolated Human Adipose Derived Stem Cells Over 72 Hours and Their Differentiation Potential into Smooth Muscle Cells Using Retinoic Acid," Stem Cell Reviews, vol. 7, no. 4, pp. 869-882, 2011.

84.F. Ginani, D. M. Soares, C. A. G Barboza, "Effect of low-level laser therapy on mesenchymal stem cell proliferation: a systematic review," Lasers in medical science, vol. 30, no. 8, pp. 2189-2194, 2015.

85.X. Chen, H. Xu, C. Wan, M. Mccaigue and L. Gang, "Bioreactor Expansion of Human Adult Bone Marrow-Derived Mesenchymal Stem Cells," Stem Cells, vol. 24, no. 9, pp. 2052-2059, 2006. 
86.J. E. Frith, B. Thomson and P. G. Genever, "Dynamic three-dimensional culture methods enhance mesenchymal stem cell properties and increase therapeutic potential," Tissue Engineering Part C Methods, vol. 16, no. 4, pp. 735-749, 2010.

87.G. Eibes, F. D. Santos, P. Z. Andrade, J. S. Boura, M. M. A. Abecasis, C. L. D. Silvaa, J. M. S. Cabrala, "Maximizing the ex vivo expansion of human mesenchymal stem cells using a microcarrier-based stirred culture system," Journal of Biotechnology, vol. 146, no. 4, pp. 194-197, 2010.

88. Y. Yang, F. M. V. Rossi, E. E. Putnins, "Ex vivo expansion of rat bone marrow mesenchymal stromal cells on microcarrier beads in spin culture," Biomaterials, vol. 28, no. 20, pp. 3110-3120, 2007.

89.S. Frauenschuh, E. Reichmann, Y. Ibold, P. M. Goetz, M. Sittinger, J. Ringe. "A microcarrier-based cultivation system for expansion of primary mesenchymal stem cells," Biotechnology Progress, vol. 23, no. 1, pp. 187-193, 2007.

90.S. Diederichs, S. Röker, D. Marten, A. Peterbauer, T. Scheper, M. V. Griensven and C.Kasper, "Dynamic cultivation of human mesenchymal stem cells in a rotating bed bioreactor system based on the Z®;RP platform," Biotechnology Progress, vol. 25, no. 6, pp. 1762-1771, 2009.

91.A. Reichardt, B. Polchow, M. Shakibaei, W. Henrich, R. Hetzer and C. Lueders, "Large Scale Expansion of Human Umbilical Cord Cells in a Rotating Bed System Bioreactor for Cardiovascular Tissue Engineering Applications," Open Biomedical Engineering Journal, vol. 7, no. 7, pp.50-61, 2013.

92.A. Papadimitropoulos, E. Piccinini, S Brachat, A. Braccini, D. Wendt, A. Barbero, C. Jacobi and I. Martin, "Expansion of Human Mesenchymal Stromal Cells from Fresh Bone Marrow in a 3D Scaffold-Based System under Direct Perfusion," Plos One, vol. 9, no. 7, pp. e102359, 2014.

93.S. Yang, K. F. Leong, Z. Du, C. K. Chua, "The design of scaffolds for use in tissue engineering. Part I. Traditional factors," Tissue Engineering, vol. 7, no. 6, pp. 679-689, 2001.

94.K. Mitsui, Y. Tokuzawa, H. Itoh, K. Segawa, M. Murakami, K. Takahashi, M. Maruyama, M. Maeda, S. Yamanaka, "The Homeoprotein Nanog Is Required for Maintenance of Pluripotency in Mouse Epiblast and ES Cells," Cell, vol.113, no. 5, pp. 631-642, 2003.

95.I. Chambers, D. Colby, M. Robertson, J. Nichols, S. Lee, S. Tweedie and A. Smith, "Functional expression cloning of Nanog, a pluripotency sustaining factor in embryonic stem cells," Cell, vol. 113, no. 5, pp. 643-655, 2003.

96.H. Darr, Y. Mayshar and N. Benvenisty, "Overexpression of NANOG in human ES cells enables feeder-freegrowth while inducing primitive ectoderm features," Development, vol.133, no. 133, pp. 1193-1201, 2006.

97.T. Tondreau, N. Meuleman, A. Delforge, M. Dejeneffe, R. Leroy, M. Massy, C. Mortier, D. Bron and L. Lagneaux, "Mesenchymal stem cells derived from CD133-positive cells in mobilized peripheral blood and cord blood: proliferation, Oct4 expression, and plasticity," Stem Cells, vol. 23, no. 8, pp. 1105-1112, 2005.

98.M. J. Go, C. Takenaka and H. Ohgushi, "Forced expression of Sox2 or Nanog in human bone marrow derived mesenchymal stem cells maintains their expansion and differentiation capabilities," Experimental Cell Research, vol. 314 , no. 5 , pp. $1147-1154,2008$. 